\title{
THE COMPOSITION OF TRACHEOBRONCHIAL SECRETIONS IN CYSTIC FIBROSIS
}

\author{
WARren S. Chernick, D.Sc. \\ The Children's Hospital of Philadelp'ria, Pa., U.S.A.
}

Since this disease was named in 1939, many other terms have been given to this syndrome notably 'mucoviscidosis'. For want of a better descriptive term, we most generally refer to it as fibrocystic disease or cystic fibrosis of the pancreas. It is obvious that, with the generalized nature of the disease, as we now view it, most of these terms are too restrictive. Cystic fibrosis is a generalized exocrine gland dysfunction with the intensity of this dysfunction varying in the different glandular sites, as well as among different patients.

In all exocrine glands that have been thoroughly studied, some type of derangement has been found.

In the pancreas, the classical pathological lesion and the resultant deficiency of pancreatic enzymes in the duodenal fluid characterize the involvement of this area. In addition, the duodenal fluid is not only deficient in pancreatic enzymes but manifests an abnormal viscosity.

One of the pronounced deviations from the normal occurs in the sweat glands where patients with cystic fibrosis manifest a much higher sodium and chloride concentration than the normal child. Such abnormalities in the sweat are utilized as diagnostic criteria and there is no question that such tests have resulted in the emergence of this disease from the category of a rare malabsorption syndrome to a major disease classification in pædiatrics.

Studies conducted on parotid gland secretory activity (Barbero and Chernick, 1958) have indicated that children with cystic fibrosis show a significantly higher flow rate than control children. The exact significance of this effect and its interrelationship to other exocrine gland abnormalities is not known at the present time but it does, once more, indicate the generalized nature of involvement by this disease.

Another glandular site which we have recently studied is the submaxillary gland (Chernick and Barbero, in press). Analyses have shown the presence of a turbid, insoluble material occurring in the submaxillary saliva of children with cystic fibrosis as compared to a clear, transparent saliva observed in control children. The secretory response of this gland shows a definite deviation, in many respects, from the normal glandular secretory pattern.

All of these exocrine gland dysfunctions mentioned form an integral part of the overall disease process and are of vital research significance in the eventual elucidation of the pathophysiological mechanism associated with this disease; however, from a therapeutic viewpoint, the effects can be controlled or are of little clinical significance.

Unfortunately, the abnormality associated with the tracheobronchial secretions is difficult, if not impossible at the present time, to control and the continual accumulation of these secretions constitutes the major problem in arresting the progression of this disease.

The extent of accumulation associated with these secretions, I think, can best be seen in the following illustrations:

Fig. I is a top view of the larynx and trachea taken of a patient with cystic fibrosis at autopsy. The thick, muco-purulent secretions occupy and obstruct the tracheobronchial area.

Fig. 2 illustrates the presence of such secretions throughout the entire tracheobronchial tract as indicated by the emergence of this muco-purulent secretion from the terminal bronchioles on this cut section.

Interestingly, we were able in a cut section of a bronchiole to obtain Figure 3 -indicating the central position of bacteria completely surrounded by mucus.

The extent of pulmonary damage associated with this progression is varied and Fig. 4 indicates the characteristic pathology seen in advanced cases at autopsy. The emphysematous lungs show patches of atelectasis.

The serious obstruction produced by the secretions of the tracheobronchial tract in cystic fibrosis indicated the necessity for an investigation of some of the physical and chemical characteristics of this material.

Utilizing tracheobronchial secretions obtained 


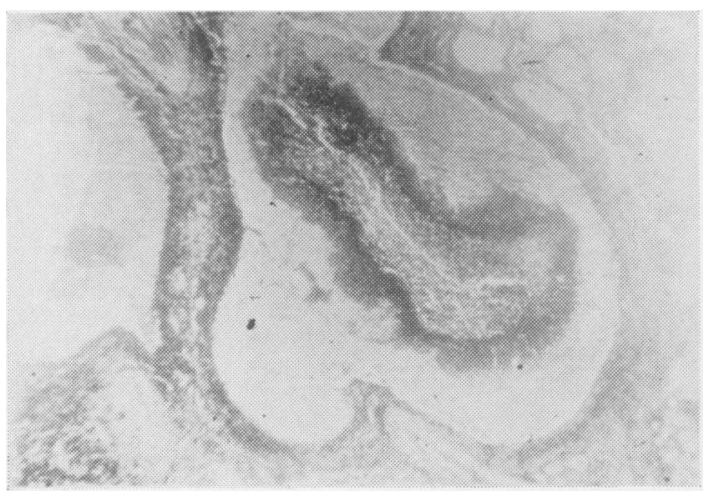

FIG. I.

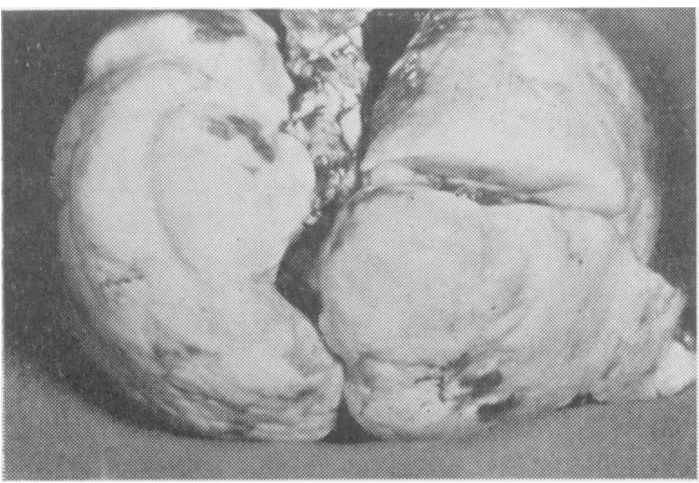

FIG. 3.

TABLE I

Organic Analysis of Tracheobronchial SECRETIONS

\begin{tabular}{|c|c|c|c|c|c|c|}
\hline & $\begin{array}{c}\% \\
\text { Dry } \\
\text { Wt. }\end{array}$ & $\begin{array}{l}\% \mathrm{~N} \\
\text { Dry } \\
\text { Wt. }\end{array}$ & $\begin{array}{c}\% \\
\mathrm{CH} \\
\text { Dry } \\
\text { Wt. }\end{array}$ & \begin{tabular}{|c|}
$\%$ \\
Hexo- \\
samine \\
Dry \\
Wt.
\end{tabular} & $\begin{array}{c}\% \\
\text { Li- } \\
\text { pids } \\
\text { Dry } \\
\text { Wt. }\end{array}$ & $\begin{array}{l}\% \\
\text { DNA } \\
\text { Dry } \\
\text { Wt. }\end{array}$ \\
\hline Cystic fibrosis & 13.16 & 12.0 & 3.1 & 2.09 & 16.4 & 10.2 \\
\hline No. of samples & 39 & 15 & I I & 8 & 5 & 14 \\
\hline Bronchiectasis & 6.01 & I 1.4 & 3.6 & 2.18 & 19.9 & 7.4 \\
\hline No. of samples & $3^{8}$ & 12 & 10 & 6 & 5 & Io \\
\hline
\end{tabular}

by bronchoscopy from patients with cystic fibrosis and bronchiectasis, an investigation was made of some of the major inorganic and organic constituents of these secretions (Chernick and Barbero, 1959).

Values for some of the organic components are given in Table 1 .

As can be seen, the mean per cent. dry weight in cystic fibrosis secretion is twice that observed in the

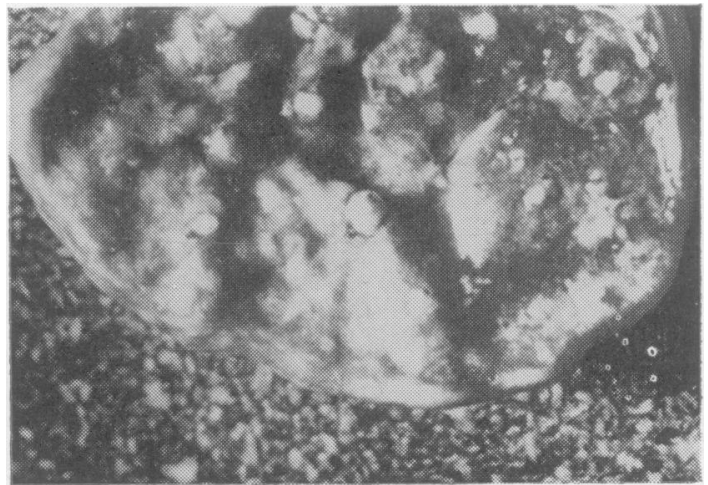

FIG. 2.

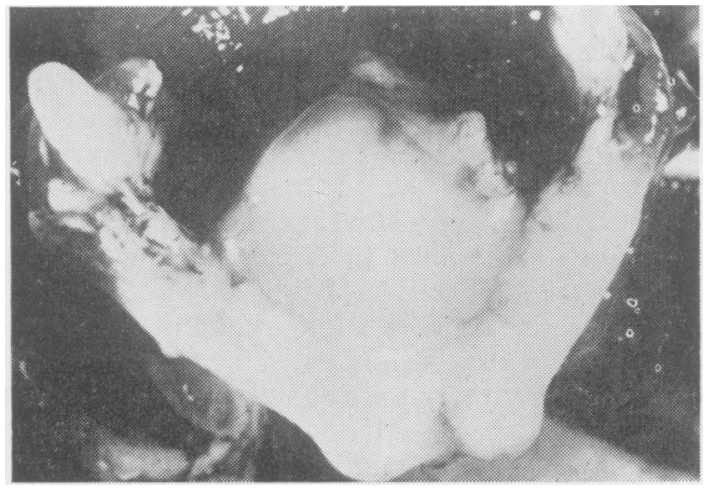

FIG. 4.

TABLE 2

INORGANIC ANALYSIS OF TRACHEOBRONCHIAL SeCRETIONS

\begin{tabular}{l|c|c|c|c|c|c|c}
\hline & $\begin{array}{c}\% \\
\text { Dry } \\
\text { Wt. }\end{array}$ & $\begin{array}{c}\text { Wet } \\
\text { Wt. }\end{array}$ & $\begin{array}{c}\text { Dry } \\
\text { Wt. }\end{array}$ & $\begin{array}{c}\text { Wet } \\
\text { Wt. }\end{array}$ & $\begin{array}{c}\text { Dry } \\
\text { Wt. }\end{array}$ & $\begin{array}{c}\text { Wet } \\
\text { Wt. }\end{array}$ & $\begin{array}{c}\text { Dry } \\
\text { Wt. }\end{array}$ \\
\hline Cystic fibrosis & 13.16 & 0.88 & 6.58 & 0.25 & I.7 & 0.08 & 0.5 I \\
\hline No. of samples & 39 & 34 & 34 & 23 & 23 & 24 & 24 \\
\hline Bronchiectasis & 6.01 & 0.96 & 13.42 & 0.34 & 4.7 & 0.10 & 1.31 \\
\hline No. of samples & 38 & 33 & 33 & 26 & 26 & 26 & 26 \\
\hline
\end{tabular}

bronchiectatic secretions. It is evident that the fluid component in the bronchiectatic specimens is much greater than that found in the cystic fibrosis secretions. The means and ranges for content of nitrogen, total carbohydrates, hexosamine and lipids, when based on per cent. dry weight are very similar. DNA was the only component found to be significantly different in the two groups, with a higher content in the cystic fibrosis secretions. Looking at the inorganic constituents (Table 2) 
TABLE 3

INORGANic ANALysis of Tracheobronchial SECRETIONS

\begin{tabular}{|c|c|c|c|c|}
\hline & \multicolumn{2}{|c|}{$\% \mathrm{CA}$} & \multicolumn{2}{|c|}{$\% \mathbf{P}$} \\
\hline & \begin{tabular}{c|} 
Wet \\
Weight
\end{tabular} & $\mid \begin{array}{c}\text { Dry } \\
\text { Weight }\end{array}$ & $\begin{array}{c}\text { Wet } \\
\text { Weight }\end{array}$ & $\begin{array}{c}\text { Dry } \\
\text { Weight }\end{array}$ \\
\hline Cystic fibrosis & 0.024 & 0.185 & 0.17 & 0.89 \\
\hline No. of samples ... & 15 & 15 & 5 & 5 \\
\hline Bronchiectasis & 0.012 & 0.180 & 0.07 & 0.74 \\
\hline No. of samples .. & 17 & 17 & 5 & 5 \\
\hline
\end{tabular}

these data show that the amount of sodium found, based on the total secretion and the amount available to the solid components, is much less in the cystic fibrosis secretion than in the bronchiectatic material. No significant difference was noted in the potassium concentration between the two groups.

The calcium content in the total cystic fibrosis secretion was found to be twice that found in the bronchiectatic material (Table 3).

The striking difference in the content of sodium, computed on a dry weight basis, found in these two types of secretion raises an interesting question as to the relationship of sodium to the peculiar physical characteristics of cystic fibrosis secretion. Kwart and Shashoua (I957) have proposed a structure (Fig. 5) for snail mucus in which a mucopolysaccharide is cross-linked to a mucoprotein by the divalent calcium ion. They found that snail mucus could be extracted by solutions of salts containing any type of monovalent cation, whereas no extraction was possible by solutions of salts of divalent cations. They postulated that monovalent cations can exchange with the calcium and hence diminish the branched or cross-linked nature of the mucus to increase solubility. They also observed that the intrinsic viscosity of snail mucus was at a maximum in a solution of calcium chloride and offered the explanation that a lack of hydrolysis or ion-exchange of calcium was manifested in the presence of excess calcium.

Experiments performed in our laboratory indicated that the viscosity of homogenated tracheobronchial secretions obtained from patients with cystic fibrosis was substantially increased upon the addition of calcium chloride. As previously indicated, the total cystic fibrosis secretion contains at least twice the amount of organic constituents and calcium ions as the total bronchiectatic secretion. Such a proportionality between an increase in dry weight and increase in calcium content lends substantial credence to the postula-

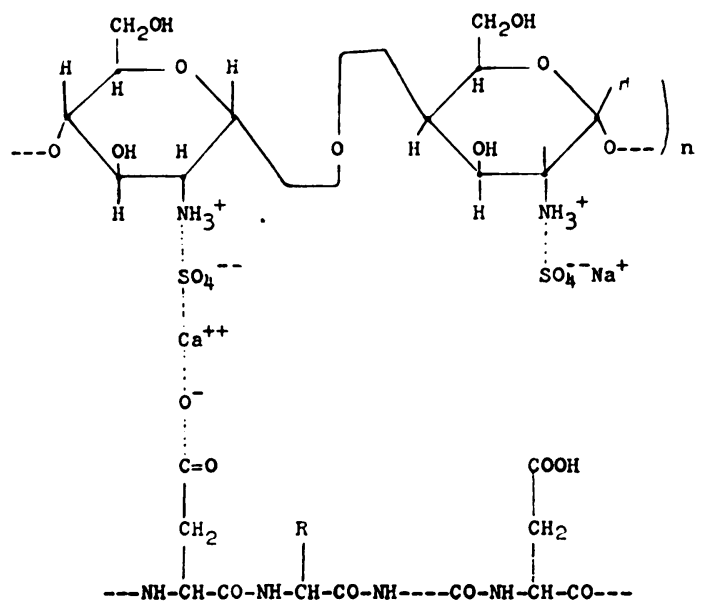

FIG. 5 .

tion that the calcium ion functions as a crosslinking agent in human mucoid material as well as in snail mucus. Consequently, it is not inconsistent to envisage an important role for calcium in addition to sodium with respect to the physical properties of the cystic fibrosis secretion. The difference in the ratio of ionic to organic constituents noted in the more viscous cystic fibrosis secretions as compared to the less viscous bronchiectatic material suggests the possibility that the physical differences exhibited in the bronchial tract could result from an alteration in the physico-chemical bonding characteristics of the secretion.

High-molecular-weight polymers are greatly influenced by the surrounding ionic concentration. In cystic fibrosis secretions, the quantity of sodium ions which are influencing the polymeric structures is less than the number affecting structures in the bronchiectatic material and, as a result of this alteration, the bonding characteristics of the calcium ions may also be affected.

The results of this investigation reveal that patients with cystic fibrosis manifest some type of defect which results in a decrease in the number of sodium ions available to affect the solid constituents of the tracheobronchial secretions when compared with the less viscous secretions in bronchiectasis. These ionic alterations could result primarily from the presence of an abnormal configuration of mucoprotein or mucopolysaccharide, which might affect the hydration properties of the material and in this manner explain the ionic alterations observed. Another possibility is that there might be a defect mediated through some portion of the ion-transport system of the secretory glands in the presence of secretion of mucoid material possessing normal polymeric structure. This latter hypothesis is interesting in 
view of the electrolyte disturbance exhibited by other exocrine glands in cystic fibrosis. Time does not permit a discussion of the pros and cons of these two alterations but present research indicates that one of the postulates may be eliminated in the near future.

\section{REFERENCES}

Barbero, G. J., and Chernick, W. S. (1958): Function of the Salivary Gland in Cystic Fibrosis of the Pancreas, Pediatrics, 22, 945.

Chernick, W. S., Barbero, G. J., and Parkins, F. (1961): Studies on Submaxillary Saliva in Cystic Fibrosis, $\mathcal{F}$. Pediat. (in press).

—_, and Barbero, G. J. (1959): Composition of Tracheobronchial Secretions in Cystic Fibrosis of the Pancreas and Bronchiectasis, Ibid., $24,739$.

Kwart, H., and Shashoua, V. E. (r957): The Structure and Constitution of Mucus, Trans. N.Y. Acad. Sci., r9, 595.

\section{Dr. LynNe ReID, M.B.(Melb.), M.R.A.C.P., M.R.C.P. (Senior Lecturer, Institute of Diseases of the Chest, Brompton Hospital)}

First I would like to thank Dr. Chernick for finding time in a very brief stay in London to come and tell us this fascinating biochemical story, because this is a disease in which discovery is being made quite fast and it is quite difficult for us to incorporate it into our clinical thinking. I shall largely be concerned just to mention how the mucus does in fact give rise to an increase of bronchial disease. The mucus is a good culture medium for a number of bacteria, and a large amount of experimental work that was done with introducing infection into the lung in fact depended on the introduction of bacteria suspended in mucin. It has been shown that the effect of mucin was not in any way to lower resistance or to enhance virulence, whatever those two terms mean, but to be related to the size of the inoculum. Injecting the bacteria suspended in mucus in fact gave them time to multiply to a largesized colony before they invaded. I have been privileged to examine quite a lot of Dr. Anderson's material from the Babies' Hospital in New York, and though clearly the basic thing here is a biochemical disturbance, once the mucus is in the bronchi it brings its own results. In both chronic bronchitis and bronchiectasis we have been interested to find that you can show a difference between the size of the bronchial glands in the normals and in patients who do produce a large amount of secretion, and one of the questions that presented in relation to these fibrocystic children was-Do they develop a gland hypertrophy at any stage, and if so at what stage ?-and when I say gland hypertrophy perhaps I should divide it up into the mucus glands in the wall of the bronchial tree and the goblet cells on the surface. To summarize briefly the findings in the material we have examined to date, it would seem that at birth you do not get an abnormal number of goblet cells in the bronchial tree. The normal lung at birth has very few goblet cells even in bronchi and certainly hardly any in the bronchiolar region of the lung. The gland ratio we have actually measured in bronchitis and in normals: the mucus gland/wall ratio, and I shall refer to this ratio as an index of the degree of hypertrophy of the glands. In the new-born fibrocystic, and up to some months, we haven't been able to show any increase in gland size, but once these children have become infected and this has continued for six years or more it is possible to find that a degree of hypertrophy has occurred, so that this does not only involve the glands in the wall but also the goblet cells in the peripheral bronchioli. It would seem that the amount of secretion produced is somehow related to what has happened after birth rather than to the intrinsic biochemical disturbance, but perhaps I can ask Dr. Chernick a question there-whether they do in fact find in the parotid and submaxillary, two glands in which infection is not clinically a problem, associated with the biochemical disturbance there is any increase in size of the gland? Some experimental work we have done using non-specific irritants to try and separate the effects of irritation from those of infection-it is possible to induce in the bronchial tree of the experimental animal a hypersecretion of mucus together with hypertrophy of mucussecreting cells while the lungs are in fact sterile, so that clearly the effect in bronchitis and bronchiectasis is largely there a question of recurrent infection and environmental conditions causing gland hypertrophy. But in this condition it may be possible to sort out whether or not the enzyme change of itself is responsible, and I would like to end by saying that in this condition as the sweat test and as the disturbance in the sweat glands became clear one hoped that from the genetic point of view we were getting close to the basic 
enzyme involved and hence to the chromosome and gene concerned with this condition, but clearly the sweat test hasn't fulfilled all the early hopes of diagnosis-some patients with fibrocystic disease are at the upper range of normal limits, and the abnormality in sweat hasn't helped to separate out the heterozygotes, so I wonder if I could ask Dr. Chernick a second question-whether he feels from what he has done whether we are getting any closer to which is the basic overall enzyme disturbance in this condition-is it perhaps concerned with calcium rather than with sodium ?

Dr. Chernick: It should be emphasized that we have concentrated most of our attention on submaxillary gland secretion recently because tracheobronchial secretions contain a variety of contaminants, notably bacteria and polymorphonucleocytes, which hinder a detailed biochemical analysis. Therefore, the utilization of submaxillary secretion provides an uncontaminated source of a sero-mucoid secretion which may be more useful in the eventual elucidation of this abnormality

In the submaxillary gland, there is a definite enlargement associated with the obstruction of the ductules by mucoid material. In this gland, there is no evidence of infection, merely an accumulation of material resulting presumably from some type of abnormality and not associated with infection.

Dr. Reid's second question relating to the basic enzyme defect is difficult to answer at the present time. I think, in the very near future, we may be able to ascertain whether the alteration in exocrine gland secretion in this disease is related to an abnormal mucoprotein or mucopolysaccaride or whether it is primarily a defect in ionic transport. Unfortunately, the basic enzyme systems which are responsible for the active transport of these ions are not known and, until such information becomes available, a definitive answer cannot be given.

My own personal opinion, at the present time, is that the alteration in ionic transport is primarily responsible for all symptoms observed in this disease including the increased viscosity of the mucoid secretions. As to whether the defect involves primarily sodium or calcium ions, the data thus far is too incomplete and much more work is needed to clarify this point. 